\title{
Nicholas WaXman
}

\section{THOSE WHO CHANGE THE WORLD}

I am a professional

I am passionate

I am educated

I am informed

I am a leader

I am a performer

I am a friend

I am a parent

I am a shoulder

I am a wall

I am an assistant

I am a coach

I am a scholar

I am a guide

I am a supervisor

I am a disciplinarian

I am an educator

I am a student

I am supportive

I am a pupil

I am a mentor

I am in the front line

68 | Offset no. IO 
I am a force for good

I am demanding

I am inclusive

I am funny

I am interactive

I am in 3D

I am respectful

I am inspiring

I am tomorrow's only chance

I am helping

I am a confidant

I am giving

I am responsible

I am unselfish

I am free

I am caring

I am understanding

I am open

I am calm

I am prepared

I am listening

and

yes, I will talk to you at recess

you are why I do what I do

I am here for you

... and you, you, you, you, you, you, you, you, you, you

and especially you. 
Those who can't, do

those who can, change

those changed, change

those who can, do

those, who change the world.

$70 \mid$ Offset no. IO 